\title{
SUDDEN DEA.TH IN INFANCY
}

\author{
Held at the Royal Alexandra Hospital for Sick Children, Dyke Road, Brighton, I \\ Chairman: Dr. T. P. Mann, M.D., M.R.C.P., D.C.H. \\ Padiatrician to the Brighton and Lewes and Mid-Sussex Hospital Groups
}

\section{Cot Death}

Dr. R. I. K. Elliott, D.M. (Consultant Pathologist, Brighton and Lewes Group Hospitals): The material I shall present is based on a survey of the post-mortem examinations of cases of cot death in this area over a five-year period, and I would like to begin by thanking my colleagues and H.M. Coroners for East Sussex and Brighton for allowing me to make this use of their reports and conclusions. You must remember that the enquiries made into these cases are not primarily medical; it is the police who interview the parents and examine the scene of the accident; and the coroner who sets the questions for the pathologist to answer. Sympathetic and helpful though they are always prepared to be, it is not reasonable, when clear and definite answers are possible on the main issues, to delay matters, and perhaps cause distress to the relatives, whilst such side issues as the identification of an infecting organism, or the histological picture in the lungs, are investigated. It has been suggested (Emery, I959) that a different picture of the causes of cot death emerges if doctors conduct the whole enquiry themselves, and that may well be so; truth has many facets. My survey is limited to the facts established at the time and the interpretations then placed on them.

A few words about the selection of cases. I have excluded those where death could be regarded as 'expected'; three infants with congenital heart disease, one with a meningomyelocœle and Arnold-Chiari syndrome who died of an ascending meningitis. They were cot deaths, but not in the sense in which we are using the term today. I have included one case that was found moribund in its cot and taken by the doctor who was called out directly in his car to hospital, but died shortly after arrival. The remainder are all, in the sense in which we are using the term, cot deaths; a total of 31 cases in the five-year period.

Table I shows statistics based on the causes of death certified by the pathologist as a result of an autopsy. The first group-mechanical asphyxiais straightforward. The circumstances of these
TABLE I

Certified Causes of Cot Death

(May, 1956-May, 196r)

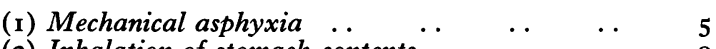

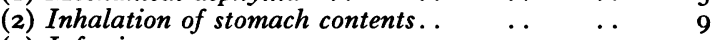

(3) Infection:

Primarily pulmonary _. . $\quad \ldots \quad 9$

Following gastro-enteritis .. $\quad \ldots \quad 3$

With otitis media $\quad . \quad$. $\quad \ldots \quad 2$

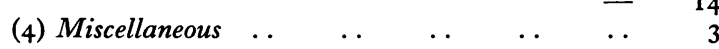

cases are interesting. One was the child of weekend visitors; there was no cot available in the house where they were staying and the child was in an ordinary bed with a harness round it; during the night, unfortunately, the child rolled out of bed and was hanged in the harness. Another was overlaid by a cat. In the third case, a rubber sheet was hung over the top of the cot and slipped off, falling over the child's head and asphyxiating it. The next case died of carbonmonoxide poisoning; the mother put an eiderdown over the child's head and fed a piece of gas tubing under the eiderdown. The final case was the youngest child of a large Irish family; it wouldn't go to sleep in its cot so the mother took it into bed with her and during the night it died; I think that this was a genuine example of a condition which was common in the days before cots were in general use, overlying.

The second group is inhalation of stomach contents. Before making this diagnosis one expects to find froth in the trachea and some consonance between the stomach contents and the material in the bronchi; this is a most interesting group and Dr. Gunther will be talking to you shortly about recent work which throws a new light on this condition.

A third group-infection-is divided up into those which are primarily pulmonary infectionsthat is, broncho-pneumonia, bronchiolitis or virus pneumonia-conditions certified as bronchiolitis or broncho-pneumonia following gastro-enteritis; 
TABLE 2

Distribution by Pathologist

\begin{tabular}{|c|c|c|c|c|c|c|c|}
\hline & & & A & B & $\mathrm{C}$ & $\mathrm{D}$ & $\mathbf{E}$ \\
\hline Mechanical asphyxia & & . & 2 & - & $\mathbf{I}$ & 2 & - \\
\hline Inhalation of stomach & contents & s. . & 8 & - & - & - & $\mathbf{I}$ \\
\hline Infective conditions & $\ldots$ & $\ldots$ & 4 & 4 & 3 & 3 & - \\
\hline Miscellaneous $\quad \ldots$ & . & . & $\mathbf{I}$ & I & $\underline{-}$ & I & - \\
\hline Totals & $\ldots$ & .. & I 5 & 5 & 4 & 6 & $\mathbf{I}$ \\
\hline
\end{tabular}

and broncho-pneumonia combined with otitis media. This forms the largest group of 14 cases. Finally, we have a miscellaneous group of three cases which I have not assigned elsewhere, because in one I do not know the cause of death, in another case the child was a Mongol and had a congenital heart as well as showing signs suggestive of inhalation, and the third was an epileptic and might have died as a result of an epileptic fit, and it also had a cerebral thrombosis.

From these figures it looks as though about half the cases are due to infection and the other half to other causes; but as the next table shows, it is not quite so straightforward as that; the diagnosis made is not so much a function of what the pathological findings are, as of the pathologist who finds them.

As Table 2 shows, half of the 31 post-mortems were performed by pathologists $\mathrm{A}$ and $\mathrm{E}$; they found, in 16 cases, nine which they ascribed to inhalation of stomach contents, and only four which were due to infection. Pathologists B, C and $D$, on the other hand, found ten cases of infection, and none of inhalation of stomach contents, in a total of 15 post-mortems. I do not know what a statistician would say, but I do not feel that this distribution is entirely due to chance. There is no doubt that the prevalent view over the past few years has been that the majority of these deaths are the result of infection (see, for example, annotation, Brit. med. F., 1957) and this opinion is reflected by pathologists $B, C$ and $\mathrm{D}$, but not by pathologists $\mathrm{A}$ and $\mathrm{E}$-judging by their reports. Who is right and who is wrong is less important, in this context, than the fact that the diagnosis varies with the pathologist; and no doubt you will bear that in mind when you hear statistics put forward in support of a particular point of view.

It might seem a simple matter to carry out bacteriological studies and abide by the results; but I have already mentioned the undesirability of delay in these cases. Another point is that cultures often raise more problems than they solve. A dead body in bed in a warm room is an excellent medium for bacterial growth; which organism, if any, out of the resultant mixture, is
TABLE 3

Seasonal Incidence of Cot Death

$\begin{array}{lllllllll}\text { Jan. } & \ldots & - & \text { May } & \ldots & - & \text { Sept. } & \ldots & 3 \\ \text { Feb. } & \ldots & 4 & \text { June } & \ldots & 5 & \text { Oct. } & \ldots & - \\ \text { March } & \ldots & \mathbf{2} & \text { July } & \ldots & \mathbf{3} & \text { Nov. } & \ldots & 4 \\ \text { April } & \ldots & \mathbf{8} & \text { August } & \ldots & \text { I } & \text { Dec. } & \ldots & \text { I }\end{array}$

to be regarded as the pathogenic one ? In fact of the nine cases regarded as primarily pulmonary infections, only two were cultured: one gave a mixed growth of $H$. influenza and pneumococci, the other a heavy growth of $B$. coli. Because an infection had been expected from the autopsy findings, they were regarded as causative organisms.

Of the cases where the diagnosis was bronchopneumonia following gastro-enteritis, two were cultured-the gut contents and the lungs in both cases grew a pathogenic $B$. coli. That-because coliforms are common post-mortem contaminants -is a finding one must take with a grain of salt, but it was accepted as significant. Finally, two cases with otitis media-one gave no growth: I am not sure that that child had not been having antibiotics, but I have already explained the unsatisfactory position when the history is taken by the police rather than by us, so that was not established at the time or if it was it did not find its way into the notes. The other case grew $B$. coli and pneumococci and again that was regarded as a significant result.

Another factor which has a bearing on the question of infection is the seasonal incidence. In fact as you see in Table 3 our cases were spread out relatively evenly through the year: April with eight cases was the heaviest month, but there were none in May and only two in March so that this does not look like a seasonal peak; nor does any clearer picture emerge if the figures are broken down according to atiology; but then the numbers are very small.

In the majority of cases the decision as to the cause of death has been made on the appearances at autopsy and it is time to consider what these are. If it is at all possible, the pathologist tries to see the actual situation in which the child was found-on the occasions when I have done this I have been struck by the squalor of the surroundings. I feel sure that cot death is more frequent where living conditions are unsatisfactory-in houseboats or one-roomed lodgings, particularly when the mother is unmarried; but, of course, the police only encourage the pathologist's examination of the surroundings when they have a serious supicion of foul play. More usually the cot is brought to the mortuary with the infant in it placed as nearly as possible in the position in which it was found, and there is almost always 


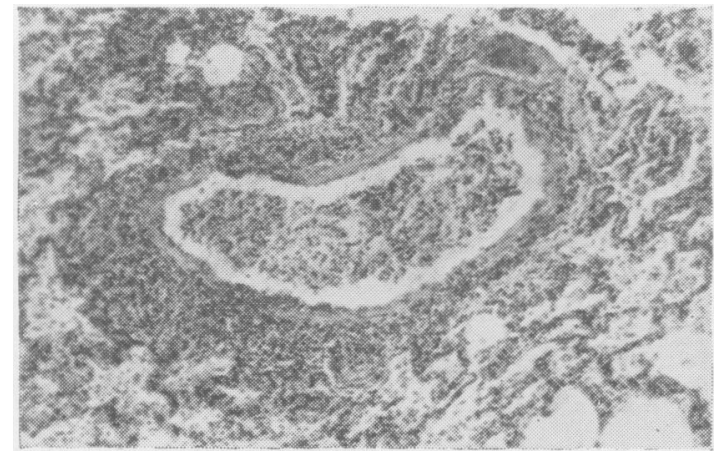

Fig. I.-Acute bronchiolitis (hæmatoxylin and eosin, $\times 80$ ). The bronchiolar epithelium has desquamated, and an inflammatory exudate fills the lumen. Degenerative changes are present in the wall, with vascular congestion and an acute inflammatory infiltrate; but the inflammation does not involve the alveoli.

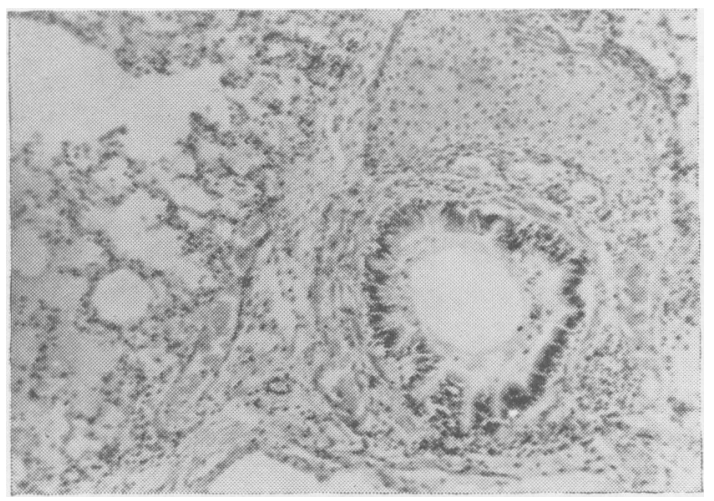

FIG. 3.-Inhalation of stomach contents (hæmatoxylin and eosin, $\times 80$ ). The inhalant in this case was rosehip syrup; the bronchial epithelium is intact; there is fluid in the lumen and in some of the alveoli, but no tissue reaction to it has occurred.

spilt vomit on the child's face, bedclothes and clothing. When the infant's head is bent back, transverse linear folds of the skin of the neck are found; these are due to hardening of the subcutaneous fat and it is important that one should not be too ready to suspect that they indicate strangulation. It is sufficiently distressing for the parents to find their child dead; they should be spared the unjust suspicion that they have made away with it. Bruises and abrasions are another matter; small babies do not injure themselves spontaneously as older children do, and any such marks found need to be accounted for.

Internally, the classical sign of asphyxia is Tardieu's spots: petechial hæmorrhages in the epicardium, the visceral pleura, and on the surface

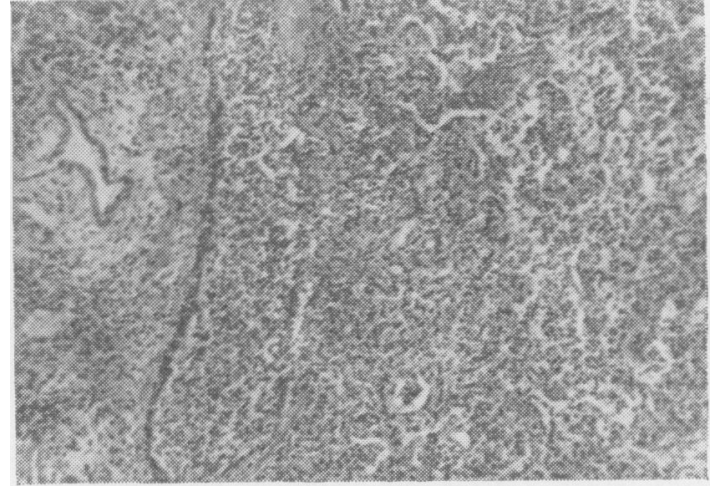

FIG. 2.-Bronchopneumonia (hæmatoxylin and eosin, $\times$ 80). An acute inflammatory reaction has almost destroyed the bronchiole and is spreading widely in the contiguous alveoli.

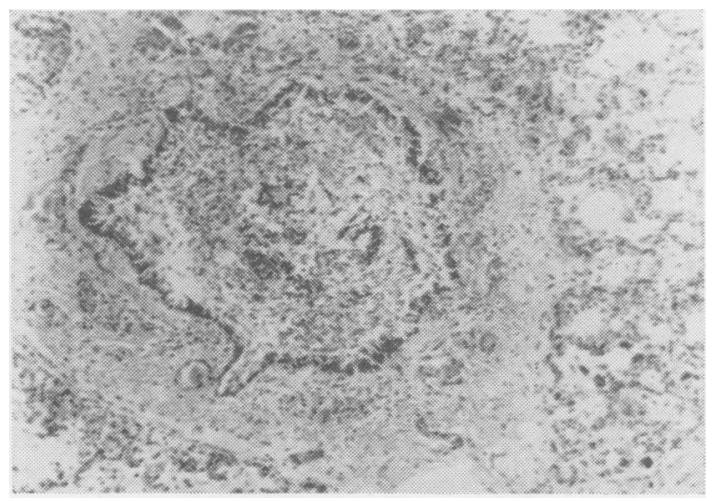

FIG. 4.-Inhalation of stomach contents (hæmatoxylin and eosin, $\times 80$ ). The inhalant here was cow's milk, and the 'explosive' disintegration of the bronchial epithelium is well shown. There is some fluid in neighbouring alveoli, but no tissue reaction is seen in them.

of the thymus. These are commonly, if not invariably, present in cases of mechanical asphyxia; they are rare, in my experience, in cot death due to inhalation or infection. There is usually froth in the air passages and perhaps frank liquid as well; this may be turbid and difficult to distinguish from mucopus. This fluid, if it is compared with the stomach contents, will almost always show a close resemblance; but, of course, that would be expected whether death is ascribed to inhalation, or fulminating infection with terminal vomiting. The stomach contents are usually a mass of white milk curd, but on occasion may be empty or contain watery fluid. In older infants other material may occur, for example, potatoes and gravy. The lungs are heavier than normal and one may find fine froth visible through the 
pleural surface, the 'sub-pleural emphysema' seen in cases of drowning; this is likely only when the tracheal exudate is watery, and has frothed extensively. On the cut surface of the lungs little beads of glairy material can often be seen exuding from the lumina of the bronchi.

Histological preparations of the lungs are available in 14 of the 31 cases in this series; fortunately they are spread representatively over the different groups.

In mechanical asphyxia the lungs show œdema as the principal feature, with vascular congestion and scattered small hæmorrhages; but no exudate in the bronchi.

In the infective group the appearances vary. Four of the nine primarily pulmonary cases had lung sections prepared; one of these showed a confluent broncho-pneumonia (this was the case which yielded $H$. influenzae and pneumococci on culture) and another showed an acute bronchiolitis. In the remaining two the lungs showed congestion and œdema with no bronchial exudate or consolidation. I suppose that if an infection is really overwhelming there may be very little tissue response to it. This is not, perhaps, a very satisfying argument; but the findings were very similar in the two cases where there was concurrent otitis media; and in one of these $B$. coli and pneumococci were recovered from both lung and ear-which, one would think, was good enough evidence of infection. In spite of that the main pathology in the lungs was simple vascular congestion.

It is, however, in the inhalation group that the histology is most interesting. They do not all show the same picture, but then the stomach contents were not the same in every case. In one child who had a comforter filled with rose-hip syrup in the cot, liquid resembling rose-hip syrup in the stomach, and a large amount of froth in the trachea, the lungs show œdema only with comparatively clear bronchi and little bronchial epithelial desquamation. Two other children had in the stomach the mass of milk curd that I described a moment ago, and milky fluid and froth in the air passages. Histologically the lungs show little or no œdema, but there is an increase in alveolar macrophages with foamy cells and even on occasion giant cells-not sufficiently marked to justify the term 'lipoid pneumonia' but to a degree not found in the lungs of other children examined. The most striking feature, however, is the presence in most of the bronchi and bronchioles of a disintegrated mass of columnar epithelial cells, mixed with mucus, as though the lining epithelium had disintegrated explosively into the lumen. This appearance has been described as characteristic of cot death (Barrett,
1954; Bodian and Heslop, 1956), but it is present in three only out of the 14 cases in which sections were cut in these series-these two with milk in the stomach, and a third in which the predominant material in the stomach was potatoes and gravy; there may, of course, have been milk as well. In this last child, incidentally, positive proof of inhalation is provided by the presence of a particle of vegetable matter in the middle of the bronchial exudate.

From what I have said earlier, you will appreciate that it is not easy, from this material, to calculate what proportion of cot deaths can be put down to inhalation of milk. If you include the misadventure cases in the total, my impression is that it is about a third, with infections of one sort and another forming another third. In a larger series, and in other parts of the country, these figures might well be very different.

Dr. Mavis Gunther, M.A., M.D. (Obstetric Department, University College Hospital, London, W.C.I): Cot deaths have presented a considerable problem for many years. The RegistrarGeneral's figures showed that there were 1,432 occurring between the ages of 2 weeks and 2 years in Britain in 1955, and the number is believed to be increasing. The deaths have frequently been attributed to an unknown fulminating virus infection, but after extensive work attempts to demonstrate a causal organism, either bacteria or virus, have been unsuccessful in most cases (Banks, 1958). In 1954 Barrett had suggested that death was due in some instances to inhalation of regurgitated food and the suggestion then arose that death might sometimes be due to a modified anaphylactic shock. This seemed in the first instance unlikely since in the guinea-pig, the animal in which anaphylaxis has been so fully studied, anaphylactic death was associated with characteristic distension of the chest and a struggle lasting some minutes. Where cot death had been observed death had been quick and without a struggle.

Acting on Barrett's suggestion, Coombs and his colleagues tried to reproduce cot death in guinea-pigs. The theory was that babies might develop an immune response to the foreign proteins of their food and that if when the immune state had become established a small amount of the same protein reached the trachea and bronchi by regurgitation a baby might die in some unusual way. Accordingly, guinea-pigs were immunized by single injections of national dried milk and then when an immune response had developed a small amount of the milk was dropped into the animal's trachea. The volume used caused almost no symptoms in the non-immunized animals and in the awake immunized animals classical ana- 
phylaxis was, of course, produced. But when the experiment was repeated in animals lightly anæsthetized with nembutal to simulate sleep, death resulted after a few breaths and without any struggle. In these animals the lung histology resembled that found in infants after cot death with a characteristic showering off of the epithelium as single cells-an explosive desquamation as Dr. Elliott said-into the respiratory passages.

The next step was to look for antibodies to cow's milk in infant's serum. They were found in the sera of most babies and on titration there was a considerable scatter. When histograms were drawn of the numbers of babies, breast- or bottle-fed, in each category of titre, it was quite certain that the titre was related to the type of milk the baby had had. The titres of the babies who had been fed from the breast for six weeks were grouped in a lower range than were the titres of the babies who had received cow's milk in some form up to that time.

The sera obtained post-mortem from cot death cases were proving to have relatively high titres of antibodies to cow's milk.

One might have thought that an infant's gastric contents would soon cease to act as an antigen, but in point of fact gastric contents from cot death cases have been found to have an effect on guinea-pigs immunized to cow's milk proteins just the same and to be just as lethal as the milk proteins used in other experiments.

At the moment one can say then quite certainly there is a mechanism which could happen, reproducible in guinea-pigs: there are immune responses in practically all babies having cow's milk, and where you have a cot death selected pretty critically by the history and the lung findings you get a high antibody to cow's milk in the baby's serum.

Dr. MANN: Some babies, of course, regurgitate their feeds more than others. Is there any evidence they are more liable to sudden death of this sort ?

DR. GuNTHER: I have wondered as Dr. Mann has about the risk of cot death in babies who regurgitate a lot, but $I$ have no evidence to offer.

DR. NASH: Is there any connection between known sensitivity conditions such as eczema and asthma and cot deaths of this type ?

Dr. GunTHER: So far we cannot give any clear answer about the relation, if any, between measured antibodies to cow's milk and asthma and eczema. We are aware that we may not be measuring the type of antibody which might be responsible.

DR. ElliotT: I wonder if Dr. Gunther has any data on gastric acidity in these infants? On occasions I have tested the bronchial exudate with indicator paper to try to provide proof of inhalation; it has always been nearly neutral about $\mathrm{pH}$ 6.5 ; but when I then test the gastric contents they give a similar result. I have in mind that infants with achlorhydria might not denature protein so readily and so become sensitized.

DR. GUNTHER: I am afraid I have no fresh evidence about that but, of course, acid secretion is known to occur normally in the first days of life.

\section{REFERENCES}

Annotation (1957): Sudden Death in Infancy, Brit. med. F., i, I4I I.

Banks, A. L. (1958): An Enquiry into Sudden Death in Infancy, Monthly Bull. Minist. Hlth Lab. Serv., r7, 182.

Barrett, A. M. (r954): Sudden Death in Infancy, in 'Recent Advances in Pædiatrics', ed. by D. Gairdner, p. 30I. London: J. \& A. Churchill.

Bodian, M., and Heslop, Barbara (1956): Sudden Death in Infancy, Abstracts, 8th International Congress of Pædiatrics, p. 91.

EMERy, J. L. (1959): Epidemiology of 'Sudden, Unexpected, or Rapid' Deaths in Children, Brit. med. F., ii, 925 .

Parish, W. E., Barretr, A. M., Coom3s, R. R. A., Gunther, M., and C.amps, F. E. (1960): Hypersensitivity to Milk and Sudden Death in Infancy, Lancet, ii, 1106.

\section{Acute Epiglottitis}

Dr. ManN: This child that died was a little girl of four who the evening before admission (she came in at 8.30 in the morning to Cuckfield Hospital) complained of a sore throat and a bit of earache on one side-she became restless and the doctor who was called at 2 a.m. noticed that her respirations were somewhat embarrassed. She was given what was presumably an antibiotic which was vomited, and brought into Cuckfield Hospital at 8.30 a.m. with a temperature of $100^{\circ} \mathrm{F}$. and respiratory rate 35 . There were marked inspiratory stridor and intercostal recession; the fauces were injected; in her chest there were only conducted sounds to hear. Over the next halfhour or so, while she was being moved to the ward, she deteriorated rapidly, with increasing stridor and cyanosis and then started to convulse. At this point one of our anæsthetists arrived and intubated her, but I am afraid she died and I actually arrived at that moment, so I did not see the child in life at all. She had obviously been a robust little girl before this sudden illness. Dr. Johnson, who is Director of our Group Laboratory in Brighton and also pathologist at Cuckfield Hospital, is going to tell you about the pathological findings.

DR. R. W. P. Johnson, M.B., Ch.B.: The only 
positive finding at the post-mortem on this infant was gross swelling and congestion of the epiglottis and a little pus in the larynx. The lower part of the respiratory tract and the lungs were quite normal, while in the rest of the body there was nothing particular to find. When we cultured the pus from the larynx it grew $H$. influenza. The cause of death was put down as acute epiglottitis. This is a rare but quite well recognized cause of sudden death in small children. There was one case reported in the British Medical fournal in I942 (De Navasquez, I942) and Dr. Francis Camps has written two papers (Camps, I953; Jones and Camps, 1957) describing a number of deaths from acute epiglottitis. In most of the cases the organism is $H$. influenza, type $\mathrm{B}$, although in some Camps got a growth of hæmolytic streptococci. This condition comes on very suddenly, usually with temperature, sore throat, difficulty in swallowing and in breathing, and the progress is very rapid. The toxæmia and shock seem to be very extreme and the children die, usually within about six hours. The diagnosis and treatment are rather difficult because there is not much time - the only way to make the diagnosis, I think, is to see the swollen congested epiglottis sticking up at the back of the throat. The treatment for $H$. influenze infections is to give chloramphenicol-I think the pædiatricians would agree with that-and the question of a tracheotomy must be considered. One would imagine that a tracheotomy would be of more value in this condition than in acute laryngotracheo-bronchitis because the inflammation is all up in the larynx, but there is not very much time to do anything in the way of treatment unless the diagnosis is made straight away; sometimes the children have convulsions and then die and all you find at the post-mortem is a grossly swollen epiglottis. The specimen in this case is not as striking now as at the time of post-mortem -you cannot see the congestion very well, but I think the swelling of the epiglottis is quite clear (Fig. 5).

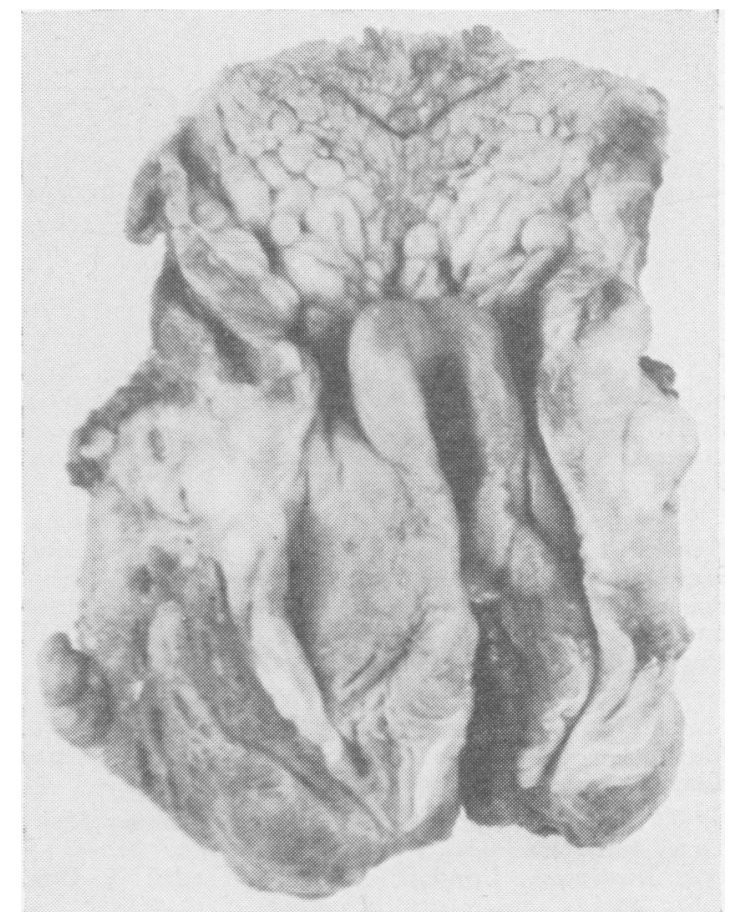

Fig. 5.-Post-mortem specimen showing gross swelling of the epiglottis.

DR. F. W. NASH, M.D., M.R.C.P., D.P.H.: This is such a rare condition that it seems unlikely that accurate diagnosis could be made in the home and treatment instituted rapidly to deal with the laryngeal obstruction. There is, however, one suggestion I can make; in small children it is often possible actually to see the epiglottis by depressing the tongue with a spatula. In this way a visual diagnosis of acute epiglottitis might be made. Emergency treatment in the home would be difficult and I can only suggest that a practitioner confronted with this particular problem should try the effect of spraying adrenalin with cocaine on the engorged ard œdematous epiglottis.

\section{REFERENCES}

Camps, F. E. (1953): Acute Epiglottitis (Acute Supraglottitis), Proc. roy. Soc. Med., 46, 281.

De Navasquez, S. (19+2): Acute Laryngitis and Septicæmia Due to H. influenza (Type B), Brit. med. F., ii, 187. Jones, H. M., and CAMPS, F. E. (1957): Acute Epiglottitis (Supraglottitis), Practitioner, 178, 223. 